WSRC-MS- $-91-015$

DE92 009831

\title{
STRESS ANALYSIS OF HYDRIDE BED VESSELS USED FOR TRITIUM STORAGE (U)
}

by

S. T. McKillip, C. E. Bannister, and E. A. Clark

Westinghouse Savannah River Company

Savannah River Laboratory

Aiken, South Carolina 29808

A paper proposed for presentation at the

Fourth ANS Topical Meeting on Tritium Technology in Fission, Fusion, and Isotopic Applications

Albuquerque, New Mexico

September 30 - October 4, 1991

and for publication in the proceedings

This paper was prepared in connection with work done under Contract No. DE-AC09-89SR18035 with the U.S. Department of Energy. By acceptance of this paper, the publisher and/or recipient acknowledges the U.S. Government's right to retain a nonexclusive, royalty-free license in and to any copyright covering this paper, along with the right to reproduce and to authorize others to reproduce all or part of the copyrighted paper. 


\section{DISCLAIMER}

This report was prepared as an account of work sponsored by an agency of the United States Government. Neither the United States Government nor any agency thereof, nor any of their employees, makes any warranty, express or implied, or assumes any legal liability or responsibility for the accuracy, completeness, or usefulness of any information, apparatus, product, or process disclosed, or represents that its use would not infringe privately owned rights. Reference herein to any specific commercial product, process, or service by trade name, trademark, manufacturer, or otherwise does not necessarily constitute or imply its endorsement, recommendation, or favoring by the United States Government or any agency thereof. The views and opinions of authors expressed herein do not necessarily state or reflect those of the United States Government or any agency thereof. 


\author{
S.T. McKillip, C.E. Bannister, and E.A. Clark \\ Westinghouse Savannah River Company \\ Savannah River Laboratory \\ Aiken, SC 29802
}

\begin{abstract}
A prototype hydride storage bed, using LaNi4.25Al0.75 as the storage material, was fitted with strain gages to measure strains occurring in the stainless steel bed vessel caused by expansion of the storage powder upon uptake of hydrogen. The strain remained low in the bed as hydrogen was added, up to a bed loading of about 0.5 hydrogen to metal atom ratio $(\mathrm{H} / \mathrm{M})$. The strain then increased with increasing hydrogen loading, up to the maximum loading $(-0.8 \mathrm{H} / \mathrm{M})$. Different locations exhibited greatly different levels of maximum strain. In no case was the design stress of the vessel exceeded.

\section{INTRODUCTION}

Thermonuclear fusion reactors will require extensive hydrogen isotope storage and handling facilities. Storage of hydrogen isotopes using metal hydride systems is safe, compact, and proven. Hydride storage systems (or storage beds) consist of a reversible hydrideforming compound, usually in powder form, contained in vessels connected to hydrogen gas handling (manifold) systems. The storage and release of hydrogen isotopes is accomplished by adjusting the temperature of the bed, and suitable control of hydrogen pressure in the gas manifold. A new tritium handling facility (Replacement Tritium Facility, RTF) at the Savannah River Site will use various metal hydrides to process hydrogen isotopes, in horizontal hydride storage beds.

Although it is well established that hydrogen storage compounds expand significantly upon hydride formation, little was known of the forces this expanding powder exerts on the container vessel. It was unclear whether the powder in the RTF storage beds would simply expand into the free volume at the top of the bed, or whether the powder would push against the vessel walls, generating stress in the walls (and at what magnitude). The goal of the work described here was to characterize the stress caused by hydride expansion in a prototype hydride storage bed vessel, under typical operating conditions.

\section{EXPERIMENTAL}

Strain gages were attached to the external surface of a prototype storage bed vessel that was fabricated from Type 304L stainless steel (Fig. 1). At most locations, both circumferentially and longitudinally oriented gages were used. Strain gage rosettes were installed at locations 17,15 and 13 in later experiments, enabling the components of strain in three directions to be measured at these locations. The measured strain was converted to stress using equations of elasticity for thick walled tubes with ends capped 1 .

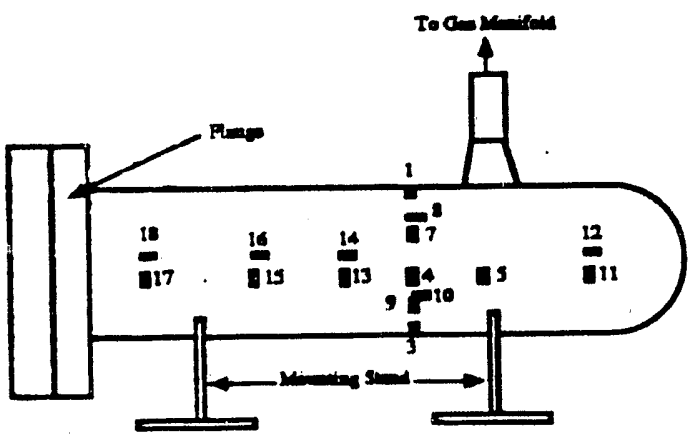

Figure 1. Diagram of Hydride Storage Bed Vessel, indicating Strain Gage Location and Orientation. 
A gas manifold system allowed controlled amou'nts of hydrogen gas to be absorbed by the powder in the bed. Hy rogen was removed from the bed (v.lloaded) by heating the vessel using heating tape and evacuation by a mechanical pump. The bed loading during each cycle, or concentration of hydrogen absorbed by the storage powder, was calculated using the Ideal Gas Law and the measured free volume in the bed. The vessel contained LaNi4.25 $\mathrm{Al}_{0.75}$ powder, (supplied by Ergenics, Inc.); the powder occupied about $72 \%$ of the interior volume of the vessel.

Each cycle of hydriding consisted of adding aliquots of hydrogen gas to the bed at ambient temperature, resulting in increased levels of average hydrogen to metal atom ratio $(\mathrm{H} / \mathrm{M})$ in the bed. The resultant exterior vessel strain was measured at each level of H/M. All strain measurements were made within 1 Kelvin of ambient temperature (monitored using surface thermocouples on the vessel exterior and thermocouple probes inserted into the storage powder); this required waiting several hours for the bed to cool after the bed absorbed each aliquot of hydrogen. (LaNi4.25 $\mathrm{Al}_{0.75} \mathrm{H}$ formation is exothermic.) Measurement of strain at ambient temperature was necessary because of the temperanure sensitivity of strain gages.

The hydriding experiments were performed in three series, to determine the effects of cycling and of bed leveling on the observed stress (Table I). Prior to Cycles 1 and 17, the bed underwent a leveling procedure using a tilting table that caused the powder to have a level profile in the bed (determined radiographically). The bed was tipped on its end after Cycle 10, to force the powder to flow to one end of the bed, and thus cause the powder profile to be unlevel.

\begin{tabular}{|lll|}
\hline $\begin{array}{l}\text { Cycle } \\
\text { Numbers }\end{array}$ & $\begin{array}{l}\text { Vessel } \\
\text { Volume } \\
\text { Filled }\end{array}$ & $\begin{array}{l}\text { Leveled or } \\
\text { Unleveled }\end{array}$ \\
\hline $1-10$ & $72 \%$ & Leveled \\
$11-16$ & $72 \%$ & Unleveled \\
$17-18$ & $69 \%$ & Leveled \\
\hline
\end{tabular}

Table I. Schedule of hydride cycling experiments, indicating the fillage and leveling of each series.

\section{RESULTS}

All locations exhibited little stress with increasing bed hydrogen content during each hydrogen loading cycle until $\mathrm{H} / \mathrm{M}=0.5$, at which point the stress rose rapidly with $\mathrm{H} / \mathrm{M}$ up to the highest loading in each cycle. The circumferential stress was always the largest stress measured at all locations. Results comparing stress at locations around the circumference of the bed will be presented first, followed by a comparison of stress at locations along the length of the bed, at the side. Stress under partial unloading of the bed is then discussed, followed by cycling effects and effects of unleveling the storage powder.

\section{Stress Around Circumference}

At a given location along the length of the bed, the largest stress occurs at the sides (Fig. 2). This diameter of the cross-section of the bed is completely occupied by powder (Fig. 3). 


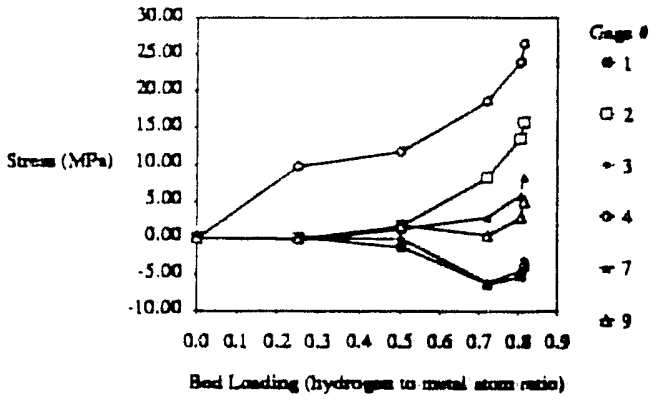

Figure 2. Circumferential Wall Stress, Gages Located Around a Circumference of Bed (gage locations given in Fig.1)

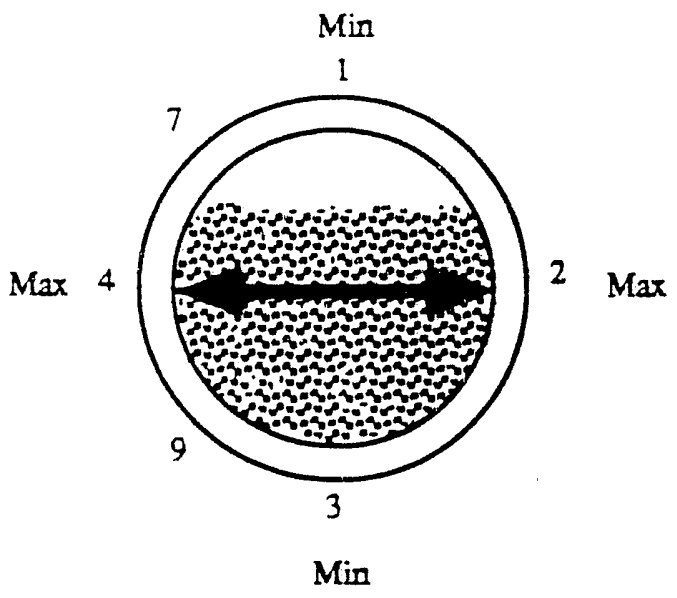

Figure 3. Diagram of Cross-Section of Hydride Bed, Indicating Maximum Stress at Sides. Corresponds with Whole Diameter Occupied By Powder. Gage locations indicated.

\section{Stress Along Bed Length}

The circumferential stress at locations along the sides of the vessel varies markedly with location (Fig. 4). This variation could be caused by: a) location dependant external constraint, imposed by support brackets and by the end flange (that allowed replacement of powder) (Fig. 1), b) shift of powder near the top (indicated by radiography) during gas transfer, or c) fine sized activated powder flowing along the top to the end when the bed was unleveled before cycle 11 . The experimental apparatus used here could not be used to determine which of these (or other factors) contributes to the variation in wall stress with location along the length of the bed.

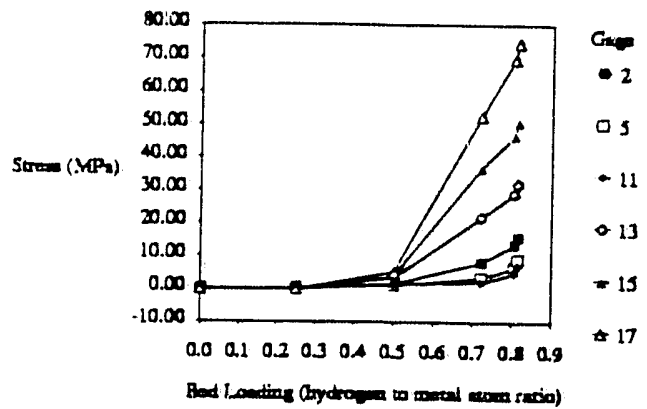

Figure 4. Circumferential Wall Stress, Gages Located Along Length of Bed (gage locations given in Fig. I)

\section{Stress During Hydrogen Unloading}

When hydrogen is removed from the bed, the stress in the walls falls rapidly to zero. This occurs even when the bed is only slightly unloaded; a series of partial unloadings and reloadings indicates that hydriding a completely empty bed causes the greatest vessel wall stress (Fig. 5) 


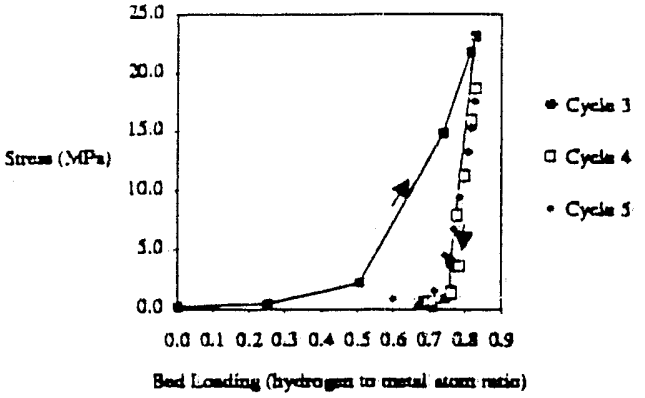

Figure 5. Circumferential Stress at Gage 2 During Cycles $3,4,5$. Only Partial Unloading (H/M always $>0.6$ as shown).

Cycling

No systematic change of wall stress was observed with cycling (Fig. 6). (The data shown here is for those cycles having $\mathrm{H} / \mathrm{M}$ that bracketed 0.8 ; extrapolation stress of other cycles from lower $\mathrm{H} / \mathrm{M}$ produced unreliable results.) The number of cycles investigated here is quite small compared to typical life of storage beds.

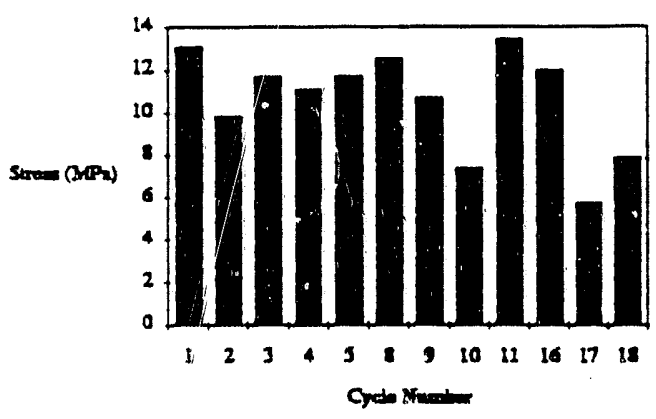

Figure 6. Interpolated Maximum Stress at $\mathrm{H} / \mathrm{M}=0.8$, Gage 11 .

\section{Unleveling}

The fraction of the cross-section occupied by powder at a given position along the length of the bed was estimated using radiographic images made after
Cycle 10 (leveled bed), and after Cycle 11 (unleveled bed). The effect of powder level on observed stress was greatest at locations nearly full with powder (Fig. 7). This indicates that to minimize stress, a substantial free space should exist above the powder in the bed at all locations.

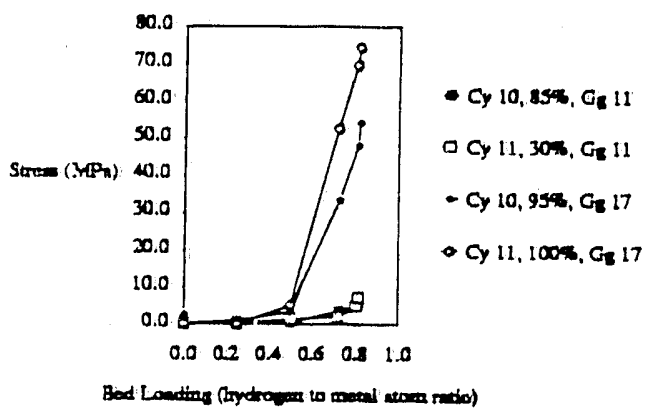

Figure 7. Effect of Unleveling on Wall Stress for Gages 11 and 17 (Level as Indicated). (Bed unleveled before Cycle 11.)

\section{Pressurizing With Helium}

At the completion of experiments, the vessel was pressurized with helium to confirm the functioning of the strain gages and their associated electrical detection system. The strain gage readings were converted to helium pressure and both circumferential and longitudinal gages agreed well with the pressure measured by the pressure transducer (Fig. 8). 


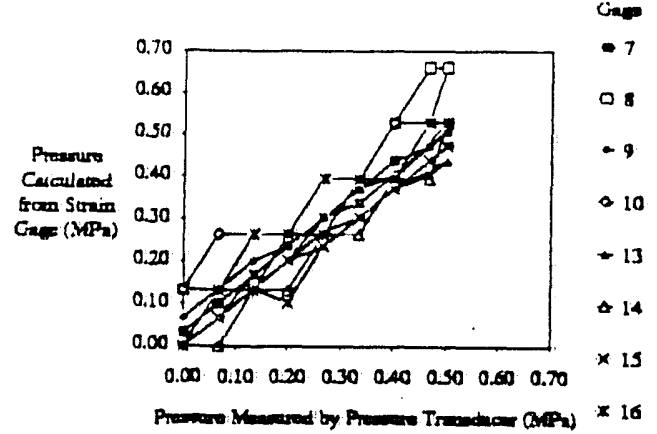

Figure 8. Helium Pressure in Bed Calculated from Strain Measurements versus Helium Pressure Measured by Pressure Transducer.

\section{DISCUSSION}

The variation of wall stress with location indicates that the powder does not flow to equalize pressure when it expands as a fluid would do, but rather pushes against itself and the walls of the container and remains in place. This was confirmed by radiography of the bed before and after hydride formation. However, the stress state in the vessel was similar to that of a pressurized fluid in that the circumferential stress was the largest stress measured at all locations. The Mohr's Circle construction, used with strain gage rosette measurements (at locations 17, 15, and 13, Fig. 1), showed that the maximum principle stress was with $6^{\circ}$ of the circumferentiai stress.

The results of this study are qualitatively similar to those found earlier by Kawamura, Ono and Mizuno 2 . They found an increasing vessel stress with increasing hydrogen absorption, and reduced stress upen dehydriding, in agreement with this study. A low but measurable stress at $\mathrm{H} / \mathrm{M}$ lower than 0.5 was found. They also found a decreased maximum stress after the first hydride cycle, in contrast to the irregular variation of maximum stress with cycling found here. The LaNis powder they used underwent ten cycles of activation before the stress measurements were made; in the present study the powder in Cycle 1 and Cycle 17 was unactivated, asreceived powder, and activation occured during the experiments reported here.

No theory currently exists relating the expansion of a given hydride powder with the stresses generated in the container wall. Experimental apparatus to directly measure wall stresses in hydride storage vessels is straightforward and allows assurance of container integrity under conditions of operation of the bed.

\section{CONCLUSIONS}

The expansion due to hydride formation can produce measurable stresses in the vessel wall of hydride storage beds. Below a bed loading of $H / M \sim 0.5$, the stresses are very small; they increase markedly with bed loading above this value. When the bed is unloaded, the stress in the vessel is completely relieved, even when substantial hydrogen remains in the bed. For a given location in horizontal cylindrical storage beds with a free space at the top, the greatest stress occurs at the side of the bed, corresponding to directions completely occupied by storage powder.

The wall stress can vary with location along the length of the horizontal vessel. This might be caused by the distribution of storage powder, external constraint of the vessel, and variation of particle size with location in the bed. To minimize wall stresses, storage beds should be leveled and have appreciable free space above the powder.

Direc measurement of wall stresses in prototype vessels is straightforward and allows assurance that the container can contain the stresses occurring during hydride formation.

\section{ACFNOWLEDGEMENTS}

The assistance of W.L. Moyer in performing the experiments is gratefully acknowledged. 


\section{REFERENCES}

1. W.C. YOUNG. Roark's Formulas for Stress and Strain $6^{\text {th }}$ ed., McGraw-Hill Book Co., New York, p 638 (1989).

2. M. KAWAMURA, S. ONO, AND Y. MIZUNO. "Stress Induced In Metal Hydrogen Powder Bed By Hydriding Reaction". Proceedings of International Symposium on Metal-Hydrogen Systems, Miami $F L$, pp 489-500 (1981).

*The information contained in this article was developed duriig the course of work done under Contract No. DE-AC09-89SR18035 with the U.S. Department of Energy. 

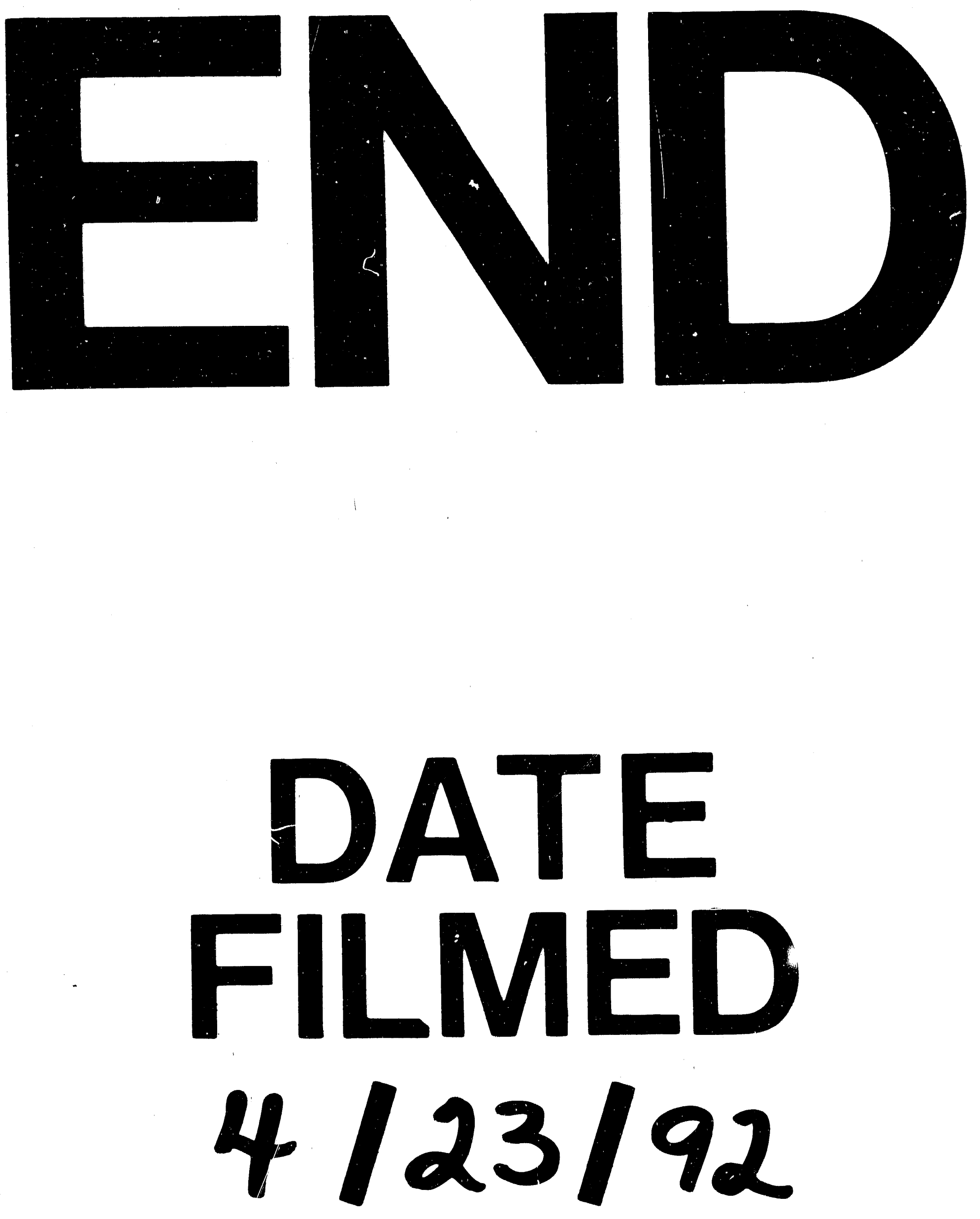

I 
